\title{
LAS CARTAS DE MÚSICA EN LA CORRESPONDENCIA GENERAL DE LA CATEDRAL DE CUENCA (1619-1697): UNA APROXIMACIÓN DESCRIPTIVA AL CONTENIDO*
}

\author{
POR \\ José LUIS DE LA FUeNTE CHARFOLÉ ${ }^{1}$ \\ Universidad de Castilla-La Mancha
}

\begin{abstract}
RESUMEN
El Archivo de la catedral de Cuenca conserva un abundante y riquísimo fondo epistolar, con documentación de gran interés en su mayoría inédita - no solo para la historia de la institución, también para la investigación relacionada con otras áreas, como la música litúrgica y las personas y oficios encargados de su organización y ejecución. El objetivo del artículo es facilitar al lector una primera descripción de los documentos de índole musical dirigidos al cabildo conquense a lo largo del siglo XVII, la mayoría firmados por nombres señeros de la música española. Esta documentación deja al descubierto la amplitud y complejidad de interacciones, intereses diversos e influencias que rodeaban la gestión de la actividad musical catedralicia.
\end{abstract}

PALABRAS CLAVE: música sacra; correspondencia; colecciones epistolares; Musicología; catedral; archivos; siglo XVII; Historia de la música.

\section{THE MUSIC LETTERS IN THE CATHEDRAL OF CUENCA GENERAL CORRESPONDENCE (1619-1697): A DESCRIPTIVE APPROACH TO THEIR CONTENT}

\begin{abstract}
The Cathedral of Cuenca Archives preserve an abundant and rich epistolary background, that comprises documentation of great interest, mostly unpublished. Not only is this interest for the history of the Institution, but also for research related to other areas, such as the liturgical music, the people and the offices that have been entrusted with its organization and execution. The aim of this paper is to provide a first description of the musical documents that had been addressed to the cathedral chapter of Cuenca during the seventeenth century. Most of these documents were signed by leading names in Spanish music. This documentation reveals the wide and complex interactions network, interests and influences that had surrounded the management of this Cathedral's musical activity.
\end{abstract}

KEY WORDS: sacred music; correspondence; collections epistolary; Musicology; cathedral; archives; 17th century; History of music.

Cómo CITAR ESTE ARTículo / CitATION: Fuente Charfolé, José Luis de la. 2019. «Las cartas de música en la correspondencia general de la catedral de Cuenca (1619-1697): una aproximación descriptiva al contenido». Hispania Sacra 71, 144: $547-562$. https://doi.org/10.3989/hs.2019.039

$\begin{array}{ll}\text { Recibido/Received } & 11-09-2017 \\ \text { Aceptado/Accepted } & 23-04-2019\end{array}$

INTRODUCCIÓN

La correspondencia general mantenida durante siglos por los cabildos representa una fuente de implementación

Este artículo es un resultado adscrito al proyecto HAR201347243-P. Patrimonio Musical de Castilla-La Mancha: Análisis crítico, recepción y edición. Ministerio de Economía y Competitividad. Programa Estatal de Fomento de la Investigación Científica y Técnica de Excelencia.

1 joseluis.fuente@uclm.es /

ORCID iD: https://orcid.org/0000-0002-7167-2176 privilegiada para la investigación histórica sobre la Iglesia y sus órganos paralelos. Su estudio permite conocer detalles insospechados sobre las personas que presidieron dichas instituciones, cuáles fueron los débitos políticos y sociales, las necesidades, los diferentes intereses que movieron las decisiones de gobierno, entender directrices sobre problemas teológicos, ${ }^{2}$ conocer los oficiales que sirvieron bajo

\footnotetext{
2 Aludimos aquí a la correspondencia del cismático cabildo de Utrecht que en pleno siglo XVII defendió la legitimidad propia para
} 
sus bóvedas y cómo se desarrollaban aquellos oficios y un sinfín de aspectos que, sin duda, enriquecerían aún más la historiografía eclesiástica y cultural de nuestro país.

A pesar de su importancia para el restablecimiento histórico en los campos religioso, político y social, las colecciones monotemáticas de correo catedralicio - no personalesson exiguas. La escasez se recrudece cuando, a causa de una clasificación determinada - en nuestro caso la música - las cartas han de ser extraídas una por una mediante un proceso de expurgación selectiva, laborioso y lento, con la dificultad añadida de tratarse de fondos tan vastos y profundos como los que atesoran los archivos de las diferentes catedrales españolas. ${ }^{3}$

Sin duda, unos de los precedentes más importantes sobre compilación de correspondencia de la segunda mitad del siglo XVII es el sobresaliente epistolario del maestro navarro Miguel de Irízar. Con casi cuatrocientas misivas recibidas en los años comprendidos entre 1663 y 1684, emitidas por más de un centenar de remitentes distintos, la mayoría músicos de fama, es uno de los más nutridos de la música española. Parece ser que Irízar aprovechó el reverso de estas cartas para conservar algunas obras de su maestro Tomás Micieces y del conquense Carlos Patiño, entre otros. Este fondo fue estudiado inicialmente por López Calo (1963 y 1965), musicólogo que publicó ciento cuarenta y dos fragmentos de distintos remitentes entre ellos el eximio maestro de la catedral de Ávila Gaspar de Liceras Isla. Décadas después el material original - depositado en la catedral de Segovia - fue revisado e investigado en su totalidad por la profesora Matilde Olarte y transcrito en una espléndida tesis doctoral defendida en 1992: un modélico estudio sistemático de gran rigor y utilidad. ${ }^{4}$

Junto al maestro Irízar, cabe señalar la también nutrida correspondencia del maestro de capilla de la catedral de Valladolid, Miguel López Camargo. Este fondo fue editado -y ampliado con material procedente del archivo privado del musicólogo tarraconense Miguel Querol- por el profesor Carmelo Caballero. Ambos testimonios permiten configurar una imagen veraz del complejo entramado en que los maestros, organistas, cantores y ministriles del barroco español se desenvolvían. ${ }^{5}$

El estudio de la correspondencia de la catedral de Cuenca proporciona -en lo musical- una visión multirrelacional, con articulaciones de alto nivel abarrotadas de intereses, influencias, informes confidenciales, datos sobre personas lugares y negocios, cartas capaces de modificar decisiones y destinos. En definitiva, su análisis permite clarificar convenciones, justificar dependencias y corregir afirmaciones muy

nombrar obispo: «Y hasta el mismo Van Espen explicaba en una carta la distinción que, a su juicio, existía entre la obligatoriedad de obediencia de los fieles respecto a una definición dogmática del Concilio de Trento y la actitud ante una bula dogmática como la Unigenitus de Clemente X|». Véase Mestre 2000: 25.

3 Véase la edición de las cartas relacionadas con Bernardo José Aldrete en Rodríguez 2009.

4 Véase Olarte 1996.

5 Véase Caballero 1990. Aun coincidiendo en el fondo y en los objetivos, la diferencia entre los estudios mencionados y el presente artículo difieren en un aspecto fundamental. Las cartas rescatadas del fondo epistolar del archivo de Cuenca no pertenecen a una correspondencia personal sino institucional y, por tanto, no contribuyen a perfilar la biografía del receptor, como en el caso de Irízar y Camargo. divulgadas y asumidas que, en el caso de la música sacra, han acabado secularmente cronificadas.

En particular, la mayor parte de las publicaciones relacionadas con la música religiosa de la capital del Júcar han soslayado la correspondencia. No aparece citada ni siquiera como recurso informativo a pesar de los numerosos y aprovechables datos que contiene, aportados de primera mano por sus protagonistas: asuntos que han pervivido con forma de protocolos escritos que permiten verificar hechos y hasta tradiciones que en otro tiempo carecían de base documental. ${ }^{6}$

El índice documental que incluye nuestro artículo puede servir para amplificar el perfil que proporcionan las fuentes recurrentes - autos capitulares, libros de obrería, cuentas y pitancería - dejando a la vista un abanico de situaciones nuevas, clientelismos, protectorados, amistades y dependencias: un plácet externo pero de clara influencia en cómo el cabildo ordenaba y gobernaba el estamento musical, no muy diferente de lo que sucedía en el resto de capillas hispanas.

Una parte inestimable de patrimonio musical atesorado en los archivos eclesiásticos ha desaparecido: el paso del tiempo, las guerras, saqueos, y la desidia humana han sido las principales causas de tan lamentable pérdida de documentación: la correspondencia musical no ha sido una excepción. Afortunadamente, a pesar de la desaparición de muchos de los originales, los asuntos suelen estar reflejados de forma escueta y esporádica en los autos capitulares. En el caso conquense, los libros de actas reflejan la noticia y el día en que llegaba alguna misiva importante - generalmente del secretario real, de comisionados en la Corte, cartas de Roma, o de cabildos y dignidades de otras catedrales- y también el momento en que fue leído y resuelto su contenido. Una parte de esas referencias no han podido ser encontradas y, por tanto, no se encuentran integradas en el apartado documental de este trabajo. Citaré a continuación algunas de ellas como ejemplo.

En primer lugar, en cuanto a la venta de libros de polifonía, destaca la firmada por Tomás Luis de Victoria «Este dia el cabildo tracto de vna carta que les habia escrito Thome de Vitoria maestro de capilla y capellan de las descalças de Madrid»; también la de otro de los maestros de las Descalzas Reales de Madrid, Sebastián López de Velasco, en que propone al cabildo la venta de un libro de polifonía compuesto por él: «Este dia se leyo una carta de Sebastian Lopez de Velasco [...] por la cual presenta al cabildo desta Iglesia un libro de musica dividido en ocho cuerpos a ocho boçes».8 Algunas de las cartas perdidas estuvieron relacionadas con acontecimientos de estado, mencionamos la misiva enviada por el corregidor de Cuenca al teniente de

6 Véase las derivaciones de estas formas en la correspondencia privada en Amor 2013: 1038. En relación con la historia musical de la catedral de Cuenca véase Martínez Millán 1988. La correspondencia musical de la catedral de Cuenca ha sido utilizada como soporte documental en Fuente 2013. De forma mucho más amplia ha infundido una nueva perspectiva contextual en la reciente monografía La música en la catedral de Cuenca hasta el reinado de Carlos II (Fuente 2019). Gran parte del fondo mantiene las expectativas de ser relacionado con la música de la institución a que pertenece.

7 Actas Capitulares (en adelante AC). L. 89, f. 23v [22-01-1601]. Destacamos el muy interesante trabajo de Escrivá 2013, sobre la música en Las Descalzas a partir del estudio de los epistolarios de Juan de Borja.

8 AC. L. 117 , f. 28 [19-03-1629] 
deán con motivo de la consolidación de la paz con Francia tras los casamientos simultáneos de Luis XIII y Ana de Austria, y la hermana de Luis XII, Isabel de Borbón, con el que después sería Felipe IV: «propuso al cabildo [...] hiziese hazer luminarias por los casamientos de España y Françia [...]. El cabildo acordo que se haga luminarias y hogueras $y$ se toquen las campanas y chirimias». ${ }^{9}$ Por último, la petición del organista de León, Francisco Arias Caldera, para servir su oficio en la catedral: «propuso como habia tenido carta para el cabildo de Francisco Arias Caldera organista de Leon en que escribe bendria a serbir a esta Iglesia». ${ }^{10}$

\section{LA CORRESPONDENCIA DE LA CATEDRAL DE CUENCA: DESCRIP- CIÓN Y GESTIÓN}

Actualmente la correspondencia de la catedral de Cuenca se encuentra ubicada dentro del Archivo Capitular en la sección III «Secretaría». Dentro de dicha sección, con el número 11 de subsección y con el epígrafe "cartas» se referencian setenta y nueve legajos de correspondencia que comprenden los años 1587 al 1869, con un contenido que supera los setenta y cinco mil documentos. A ello hay que sumar cinco legajos de cartas de Roma (1535-1695); seis legajos de registros (1606-1687); siente legajos de borradores (1688-1881); un legajo de cartas reales (1405-1857); dos legajos de correspondencia varia (1647-1862) y dos legajos de correspondencia de obispos (1366-1625). Como fondo epistolar paralelo habría que contabilizar la correspondencia perteneciente a las Secciones IV «Mesa Capitular» con ocho legajos entre 1838 y 1869, y a la Sección V «Mayordomía», con veinticinco legajos de cartas sobre diezmos, mayordomía y asuntos diversos correspondientes al periodo 1838-1841. Restan otros dos legajos de correspondencia (1661-1803) perteneciente a la Sección VII «Sede Vacante», según consta en la guía general del Archivo. ${ }^{11}$

En las catedrales la correspondencia solía ser atendida por el deán, o vicedeán. En la institución conquense la gestión epistolar fue una de las funciones del secretario del cabildo, quien estaba encargado de su lectura, tramitación y posterior respuesta, como iniciador del proceso intermedio que valoraba la pertinencia de los asuntos antes de pasarlos a la consideración definitiva del cabildo. Las peticiones y requerimientos relacionados con la música - y su puesta en práctica- estaban supervisados, además del secretario, por canónigos o prebendados comisionados al efecto que debían de dar cuenta al cabildo de sus actuaciones; en última instancia correspondía al cabildo la resolución final del asunto.

Sabemos que el cabildo de Cuenca utilizaba dos maneras preferentes de enviar y recibir el correo, dependiendo de la urgencia o importancia del mensaje: a) correo de a pie, o correo ordinario; b) estafeta, con un lugar propio en la ciudad de Cuenca, con días fijos de recogida y salida

9 AC. L. 103, f. 66v [30-10-1615]. El destacado en cursiva nos pertenece.

10 AC. L. 115 , f. 54 [28-04-1627].

11 Chacón 2001. Cabe señalar el acierto del profesor de Paleografía y Diplomática de la UAM y canónigo archivero del Archivo capitular de la catedral de Cuenca al haber elaborado esta Guía, tan versátil como orientadora e informativa. Igualmente destaca la reciente publicación de Martínez Catalán 2019, un nuevo instrumento de gran utilidad archivística e investigadora. (correo a caballo con estaciones y relevos). No se menciona ningún otro tipo de envío en las actas por lo que es evidente que a mediados del siglo XVII el servicio de correo "ordinario» era el denominado "estafeta», entonces en pleno funcionamiento:

Este dia el dicho señor dean dixo que por el correo ordinario de la estafeta se habia publicado la muerte de la Reyna nuestra señora que murio en Madrid jueves por la tarde seis deste mes [...] que el cabildo reconociese otros exemplares de casos semejantes para que en todo se cumpliese con la atencion y grandeza que se debe. ${ }^{12}$

La estafeta tenía un lugar de distribución y recogida propio en dicha ciudad castellana, tal y como fue manifestado por el cabildo al revisar el recorrido de la procesión del Corpus: "dichos maestros han declarado entre otras que unas casas que estan enfrente de la estafeta estan con notorio peligro de caerse y que en ellas hay una que es de la mesa capitular». ${ }^{13}$

\section{CONTENIDO}

Para conseguir la presente muestra ha sido necesario revisar y expurgar, en su totalidad, el continente informativo inicial: cuarenta y dos legajos completos de correspondencia con más de quince mil documentos. A partir de aquí fueron reseñadas todas aquellas cartas que tenían relación con el área musical - aunque de índole diversa- en el periodo acotado entre la fecha de la primera que fue localizada (2406-1619) y la última (09-01-1697), ambas dentro de la centuria considerada. Los noventa y seis documentos extraídos y reseñados están contenidos en el arco comprendido entre el legajo III. 239 /1 y el III. 272/2. También han sido consultados algunos legajos anteriores y posteriores hasta completar el siglo, sin obtener aporte alguno.

Los datos musicales derivados del análisis documental, considerados de forma aislada, pueden parecer exiguos e incluso anecdóticos en cierta medida, pero puestos en relación con otros son -en todo caso- básicos para penetrar en la historia - y también la intrahistoria- de la música seiscentista, en múltiples aspectos.

Aunque es obvio que no es objeto de este artículo ahondar en las relaciones ni los remitentes de este conjunto epistolar, propósito que excedería nuestros límites, sí es posible apreciar la ratio y el oficio: la mayoría fueron maestros de capilla, a los que siguieron sochantres, ministriles $y$, en menor medida, cantores y organistas (véase Tabla 1).

Por su interés, cabe aquí una breve explicación sobre la distribución y aumento en la densidad del correo detectado en fechas muy determinadas (años de 1637, 1664, 1675; bienio 1683-1684 y año 1696). La capilla de música de la catedral de Cuenca gozaba a principios del siglo XVII de un gran prestigio, entre otras razones por el trabajo desarrollado por su maestro, Juan de Castro y Mallagaray, que permaneció al frente de la institución musical durante más de 32 años. Tras la muerte del maestro en 1632, y a pesar de la preocupación del cabildo por cubrir el puesto vacante con eficacia, comenzó un periodo de inestabilidad con cambios constantes. Castro fue sucedido por el maestro valenciano,

\footnotetext{
12 AC. L. 132, f. 77 [11-10-1644]. El destacado en cursiva es nuestro.
}

13 AC. L. 418 f. 61 [29-05-1666]. El destacado en cursiva es nuestro. 
TABLA 1

Ratio cargo / correspondencia

\begin{tabular}{|l|c|c|l|}
\hline Cargo/oficio & $\begin{array}{c}\text { Número } \\
\text { de cartas }\end{array}$ & $\begin{array}{c}\text { Ratio } \\
\% \text { del total }\end{array}$ & \multicolumn{1}{|c|}{ C [Carta] } \\
\hline M. de capilla & 38 & 39,59 & $\begin{array}{l}2,11,12,13,15,18,20,21,23,33,39, \\
42,44,51,53,55,57,58,64,65,67, \\
68,70,72,82,83,84,85,86,87,88, \\
89,91,92,93,94,95,96 .\end{array}$ \\
\hline Sochantría & 13 & 13,55 & $\begin{array}{l}37,38,43,59,60,61,62,63,73,75, \\
78,80,81 .\end{array}$ \\
\hline Ministriles & 9 & 9,38 & $8,16,24,25,30,32,34,36,79$. \\
\hline Chantría & 7 & 7,30 & $48,49,50,52,54,56,66$. \\
\hline Deanato & 6 & 6,26 & $4,5,6,7,45,47$. \\
\hline Comisionados & 5 & 5,20 & $14,35,40,41,69$. \\
\hline Cantoría & 3 & 3,12 & $31,74,90$. \\
\hline Edictos & 3 & 3,12 & $9,10,17$. \\
\hline Organistas & 3 & 3,12 & $1,27,28$. \\
\hline Prioratos & 3 & 3,12 & $19,22,29$. \\
\hline Cardenales & 2 & 2,08 & $76,77$. \\
\hline Obispos & 2 & 2,08 & $3,46$. \\
\hline Libros & 1 & 1,04 & 71. \\
\hline Secretaría & 1 & 1,04 & 26. \\
\hline Total: & 96 & 100,00 & \\
\hline
\end{tabular}

Fuente: Elaboración propia.

Vicente García, hasta que fueron convocadas nuevas oposiciones en 1635, realizadas bajo la supervisión de Juan Bautista Comes. A pesar de las pruebas y del importante gasto que conllevó dicha oposición la plaza permaneció sin cubrir por la falta de suficiencia en los candidatos al puesto. Nuestro interés se polarizó en este periodo por razones obvias, lamentablemente no pudimos localizar correspondencia alguna relacionada con dicha oposición, como tampoco con el más tardío nombramiento de Alonso Fernández en 1636. A partir del 2 de mayo de 1637, a raíz de las gestiones promovidas por el cabildo para cubrir el magisterio de capilla, ${ }^{14}$ encontramos una gran concentración de solicitudes y recomendaciones personales llegada de múltiples lugares de España para cubrir dicho oficio (véase Tabla 2); el estudio de esta circunstancia y sus derivaciones puede ser ampliado en Fuente (2019: 222-228).

\section{TABLA 2}

Nudo (oposición a maestro de capilla de 1637)

\begin{tabular}{|c|c|l|l|}
\hline C & Data & \multicolumn{1}{c|}{ Remitente } & \multicolumn{1}{c|}{ Puesto / Oficio } \\
\hline 11 & $20-05-1637$ & Luis Julián & Maestro de Capilla \\
\hline 12 & $30-05-1637$ & José de Rada & Maestro de Capilla \\
\hline 13 & $08-06-1637$ & Luis de Garay & Maestro de Capilla \\
\hline 15 & $05-07-1637$ & José de Rada & Maestro de Capilla \\
\hline 16 & $07-07-1637$ & Juan de Quesada & Maestro de Capilla \\
\hline 18 & $14-07-1637$ & Carlos Patiño & Maestro de Capilla \\
\hline 20 & $03-08-1637$ & Luis de Garay & Maestro de Capilla \\
\hline 21 & $04-08-1637$ & Juan de Quesada & Maestro de Capilla \\
\hline 23 & $10-08-1637$ & Luis de Garay & Maestro de Capilla \\
\hline 24 & $10-08-1637$ & Juan de Quesada & Maestro de Capilla \\
\hline 27 & $15-09-1637$ & Francisco Correa & Organista \\
\hline 28 & $15-09-1637$ & Francisco Correa & Organista \\
\hline
\end{tabular}

Fuente: Elaboración propia

\footnotetext{
14 AC. L. 125, f. 70 [02-05-1637]
}

Tras los magisterios de Manuel y Nicolás Tavares, Juan de Padilla, Sebastián Alfonso, José de Alcalá y Francisco Sáez, es necesario esperar al proceso de oposición de 1664 para encontrar de nuevo una mayor afluencia de correo en fecha cercana a la convocatoria. La Tabla 3 tiene que ver con la correspondencia recibida en los dos periodos de magisterio de Alonso Xuárez en la catedral de Cuenca. El primero de ellos, relacionado con la provisión del puesto, ha sido analizado con detalle en Fuente (2013: 15-55); ${ }^{15}$ en la tabla se evidencia la elevada concentración de correos y la importancia de los nombres en relación con las fechas: a) de oposición y nombramiento (1664); b) de traslado a Sevilla como maestro de capilla (1675); c) de regreso a Cuenca y comienzo de la segunda etapa (aprox. 1683); d) de muerte del maestro y nueva provisión en Julián Martínez Díaz, maestro de Jerez (1696).

TABLA 3

Relación entre nudos y magisterios vacantes (1663 a 1696)

\begin{tabular}{|c|c|c|c|}
\hline C & Data & Remitente & Puesto / Oficio \\
\hline 42 & $22-10-1663$ & Gregorio de Salinas & Maestro de Capilla \\
\hline 44 & $22-11-1663$ & Gregorio de Salinas & Maestro de Capilla \\
\hline 51 & $23-08-1664$ & Tomás Micieces & Maestro de Capilla \\
\hline 53 & $29-08-1664$ & Juan de Padilla & Maestro de Capilla \\
\hline 55 & 06-09-1664 & Tomás Micieces & Maestro de Capilla \\
\hline 57 & $12-09-1664$ & Juan de Padilla & Maestro de Capilla \\
\hline 58 & $20-09-1664$ & Andrés de Viana & Maestro de Capilla \\
\hline 64 & $25-08-1675$ & Diego José de Salazar & Maestro de Capilla \\
\hline 65 & $19-10-1675$ & Miguel Mateo de Dallo & Maestro de Capilla \\
\hline 67 & $16-11-1676$ & Miguel Mateo de Dallo & Maestro de Capilla \\
\hline 68 & $27-07-1677$ & Pedro de Ardanaz & Maestro de Capilla \\
\hline 70 & $13-03-1683$ & Juan Pacheco Montion & Maestro de Capilla \\
\hline 72 & $06-09-1683$ & Alonso Xuárez & Maestro de Capilla \\
\hline 82 & $04-07-1696$ & Sebastián Durón & Maestro de Capilla \\
\hline 83 & $24-07-1696$ & Matías Navarro & Maestro de Capilla \\
\hline 84 & $18-08-1696$ & Crisanto J. de Escobar & Maestro de Capilla \\
\hline 85 & $02-08-1696$ & $\begin{array}{l}\text { Sebastián Durón } \\
\text { (Fuente 2019: 331-332) }\end{array}$ & Maestro de Capilla \\
\hline 86 & $25-08-1696$ & Crisanto J. de Escobar & Maestro de Capilla \\
\hline 87 & 01-09-1696 & Crisanto J. de Escobar & Maestro de Capilla \\
\hline 88 & $25-08-1696$ & Juan Montero del Villar & Maestro de Capilla \\
\hline 89 & $29-08-1696$ & Juan de la Blanca & Maestro de Capilla \\
\hline 91 & $29-08-1696$ & Roque de Lázaro & Maestro de Capilla \\
\hline 92 & $30-09-1696$ & Julián Martínez Díaz & Maestro de Capilla \\
\hline 93 & $28-10-1696$ & Julián Martínez Díaz & Maestro de Capilla \\
\hline 94 & $16-12-1696$ & Julián Martínez Díaz & Maestro de Capilla \\
\hline 95 & Sin fecha & Crisanto J. de Escobar & Maestro de Capilla \\
\hline 96 & 09-01-1697 & Matías Durango & Maestro de Capilla \\
\hline
\end{tabular}

Fuente: Autor

La procedencia de las cartas recibidas es muy diversa (véase Tabla 4), sin duda destacan algunos de los compositores principales de la música catedralicia y sus lugares. Un análisis más pormenorizado puede ratificar la existencia

15 Gracias al contenido de algunas de estas cartas, el autor pudo esclarecer los entresijos de la oposición de Alonso Xuárez en la catedral de Segovia y su posterior ingreso en Cuenca. Del mismo modo se documentó el enfrentamiento entre los maestros Tomás Micieces y Juan Pérez Roldán que acabó en un auténtico desencuentro entre los músicos de Las Descalzas y de La Encarnación. Véase con mayor detalle en Fuente 2019: 281. 
TABLA 4

Maestros de capilla: origen de la correspondencia

\begin{tabular}{|c|l|l|l|}
\hline C & Nombre & Oficio & Lugar de procedencia \\
\hline 42 & Gregorio de Salinas & Maestro de Capilla & Ciudad Rodrigo \\
\hline 39 & José de Alcalá & Maestro de Capilla & Cuenca \\
\hline 23 & Luis de Garay & Maestro de Capilla & Guadix \\
\hline 21 & Juan de Quesada & Maestro de Capilla & Jaén \\
\hline 92 & Julián Martínez Díaz & Maestro de Capilla & Jerez \\
\hline 65 & Miguel Mateo de Dallo & Maestro de Capilla & Logroño \\
\hline 18 & Carlos Patiño & Maestro de Capilla & Madrid \\
\hline 33 & Vicente García & Maestro de Capilla & Madrid \\
\hline 82 & Sebastián Durón & Maestro de Capilla & Madrid \\
\hline 89 & Juan de la Blanca & Maestro de Capilla & Madrid \\
\hline 91 & Roque de Lázaro & Maestro de Capilla & Madrid \\
\hline 51 & Tomás Micieces & Maestro de Capilla & Madrid (Descalzas Reales) \\
\hline 11 & Luis Julián & Maestro de Capilla & Orihuela \\
\hline 83 & Matías Navarro & Maestro de Capilla & Orihuela \\
\hline 64 & Diego José de Salazar & Maestro de Capilla & Osuna \\
\hline 88 & Juan Montero del Villar & Maestro de Capilla & Pastrana \\
\hline 70 & Juan Pacheco Montion & Maestro de Capilla & Plasencia \\
\hline 96 & Matías Durango & Maestro de Capilla & Santo Domingo de la Calzada \\
\hline 72 & Alonso Xuárez & Maestro de Capilla & Sevilla \\
\hline 58 & Andrés de Viana & Maestro de Capilla & Sigüenza \\
\hline 12 & José de Rada & Maestro de Capilla & Teruel \\
\hline 84 & Crisanto J. de Escobar & Maestro de Capilla & Teruel \\
\hline 53 & Juan de Padilla & Maestro de Capilla & Toledo \\
\hline 68 & Pedro de Ardanaz & Maestro de Capilla & Toledo \\
\hline & & & \\
\hline
\end{tabular}

Fuente: Autor

de redes internas de información entre maestros y músicos, complicidades, influencias y recomendaciones que dejan ver en muchos casos la necesidad económica o el deseo de aspiración y promoción social del individuo, circunstancias que incidieron en la historia y que merecen ser analizadas como testimonios de nuestro pasado.

\section{CARACTERÍSTICAS FÍsicas}

\subsection{El papel}

El papel utilizado es en su mayoría verjurado, homogéneo en cuanto a calidad y tamaño. Prevalece el tamaño folio $(215 \times 315 \mathrm{~mm})$ de uso habitual por encontrarse ya comercializado en la época. La coloración presenta pequeños cambios, dependiendo de la materia prima utilizada en su fabricación, de su mayor o menor densidad y cuerpo, y de la situación y número de corondeles y puntizones. Es utilizado a veces el bifolio cuando el cuerpo de texto es amplio y en mucha menor medida el folio alto $(220 \times 330 \mathrm{~mm})$, con predominio del papel holandés en la correspondencia procedente de Roma $(220 \times 280 \mathrm{~mm})$. A pesar de que los componentes de las tintas favorecen la tendencia oxidativa $y$ corrosiva, el papel se mantiene - por su excelente calidaden buen estado de conservación general, sin corrimientos, roturas ni pérdida de información por este concepto.

\subsection{El plegado y cierre}

Normalmente las cartas referenciadas aparecen plegadas de forma semejante según el procedimiento que sigue: a) doblado transversal hacia sí, dejando el texto en la cara interna; b) segunda doblez en sentido inverso; c) última doblez realizada en sentido transversal, cuadrando el papel en octavos; d) una de las caras exteriores del folio ya plegado era utilizada para anotar el sobrescrito. ${ }^{16}$

Algunas cartas presentan manchas que bien pudieran ser de sello clausor de papel y cera roja (Fig. 1). Otros presentan alguna huella de roturas y prensado propio de los sellos de lacre. La mayoría de los documentos no contienen huella de haber sido cerrados mediante procedimiento directo, lo que no impide que hubieran sido cerrados mediante cordeles o bramantes sellados. No es descartable el uso de sobres contenedores, si bien cabe suponer que el plegado sufrido habría sido menor ya que su razón de ser no era otra que preservar la confidencialidad.

FIGURA 1

Carta del comisionado capitular en Roma, Dr. D. Raimundo Melchor y Miralles

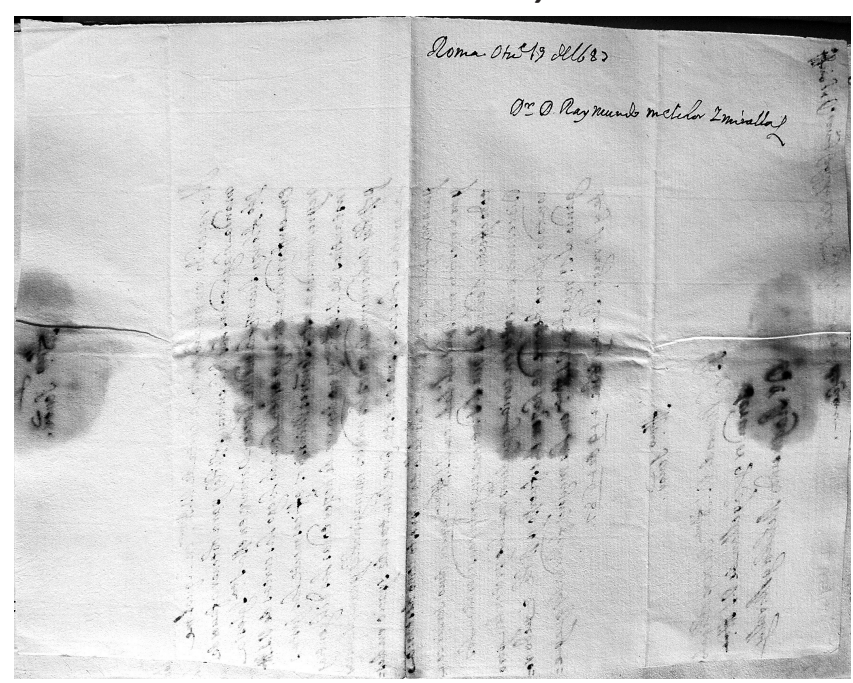

Huella de clausor de papel y cera roja. (verso) [C 69]. Fuente: E-CU III. 266/4 (44)

\section{CARACTERÍSTICAS FORMALES}

De la revisión de los documentos es posible sacar información sobre la práctica relacionada con el tratamiento y fórmulas de cortesía utilizadas, entre ellas se encontraba el uso de los márgenes como manera habitual de comunicarse respetando los privilegios, atributos y distancias diferenciadoras entre clases. Los autores parten de la mayor de las cautelas y aplican buenas dosis de astucia y habilidad de escritura para conseguir sus propósitos. La correspondencia asimétrica es articulada siempre en función del rango del destinatario - como referencian los múltiples formularios y manuales áureos que servían de auxilio a la hora de redactar las cartas - para asegurar la corrección y seguir las convenciones del momento.

Las cartas aquí reseñadas son de extensión variable, siempre determinada por el asunto y por la necesidad explicativa. Se distribuyen desde la brevedad de los autos de provisión de plazas hasta aquellas en que el remitente dictamina, informa, sugiere o aconseja respecto a un asunto

16 El lector puede apreciar los detalles del plegado en las figuras 1,2 y 3 . 
reclamado por el cabildo. La forma de expresión suele mantener cierto equilibrio entre la locución común y la opulencia. El lenguaje es cercano incluso cotidiano y gracias a su plasticidad define perfectamente la intención del remitente sin llegar nunca a la ligereza ni al descuido. El autor mantiene la corrección y decoro debidos al destinatario. En su mayoría el estilo de escritura se adapta al asunto a tratar, no contiene terminología judicial como tampoco interferencias metafóricas ni oratorias extremas. La comprensión del asunto es fácil y nunca incluyen argot profesional. Las frases son claras y cuidadas, aunque a veces algunas de ellas suelen quedar sueltas y sin vinculación definida.

\subsection{Manuscripción}

Las cartas eran escritas a mano excepto los edictos de provisión de plazas de cantores y maestros de capilla, que llevaban anexos los impresos que se colocaban al público en las puertas de la catedral, eran modelos ${ }^{17}$ generalmente en castellano con tipografía y técnica propia del Quinientos finisecular (Fig. 2).

FIGURA 2

Edicto de provisión

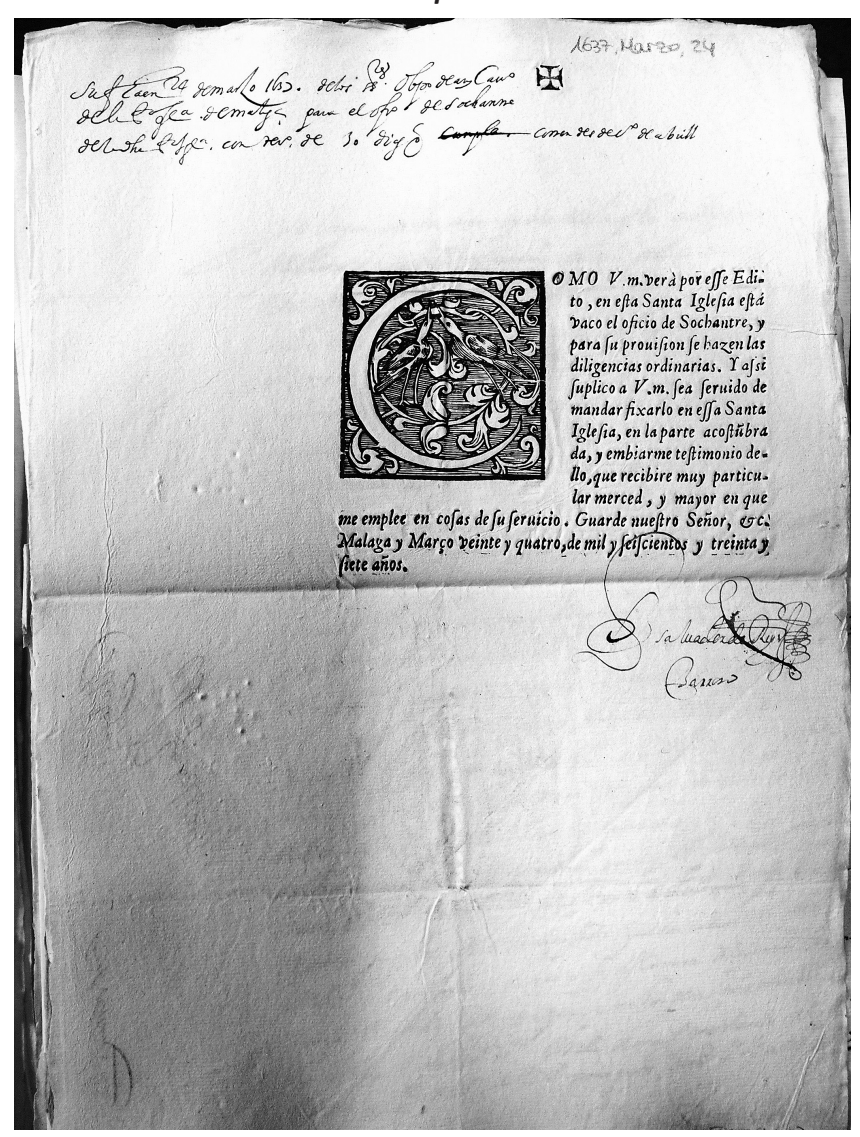

El bloque de texto aparece enmarcado por la amplitud de los márgenes. El texto en itálica es desplazado por la inicial C de gran módulo y relleno zoomórfico (garzas), ornamentado con entrelazado vegetal y volutas de típico estilo renacentista florentino. La imagen corresponde a [C 9]. Fuente: E-CU III. 252/1 (28)

17 Existen modelos mixtos de «impresos», donde había una parte correspondiente a los datos que era manuscrita, esto ocurría en algunos documentos notariales, como cartas de poder, notificaciones de prisión, penas económicas, excomunión o desahucio.
En las cartas manuscritas el tipo de letra es muy variada y personal, en la mayoría de los casos la seguridad del trazo denota una práctica habitual y regular, la letra es generalmente itálica usual, ciudadana humanística cursiva, con algún caso aislado de procesal encadenada, la capacidad de usar las abreviaturas más frecuentes y el uso de caligrafías típicas para semejar una forma escrita acorde a las reglas del decoro y el estilo. La manuscripción es a plumilla y las tintas suelen ser ferruginosas de tonalidades ocres con preferencia a tintas más oscuras. El texto aparece ajustado al folio y dispuesto en vertical, excepto en las misivas procedentes de Roma que lo hace en formato apaisado.

\subsection{Interlineado}

Es por lo general homogéneo y proporcional al tamaño de la letra. Las cartas suelen presentar una escasa descomposición silábica del texto, si bien se dan casos en que la lectura resulta dificultosa por la elevada fragmentación. Observamos también que la mayoría de los autores establecen cierto equilibrio entre el espacio en blanco y el ocupado por el texto, aunque no en todos los casos ya que a veces los márgenes acaban casi por desaparecer debido a una escritura apretada y menuda que acaba invadiendo casi la totalidad de la superficie del mensaje [C 42].

\subsection{Margen}

En el siglo XVII el uso de los márgenes no era solo una práctica de escribientes escrupulosos sino una muestra de respeto más - desde el ámbito estético- hacia el rango del destinatario. Su amplitud variaba según el estatus si bien, y contrariamente a la afirmación de Silvia Amor, en las cartas musicales conquenses no existió un criterio uniforme en cuanto a la disposición, uso y tamaño del margen: «La extensión y ubicación de los márgenes en blanco que se dejaban en las misivas eran por sí mismas una muestra de cortesía: más blanco cuanto más distinguido fuera el destinatario de la epístola o más distinción se le quisiera otorgar ${ }^{18}$

En los documentos conquenses se aprecia perfectamente la huella de una línea vertical que aparece marcada ad hoc a $1 / 3$ de la anchura del folio; en el papel verjurado es aprovechado algún corondel próximo a esa proporción como guía.

La utilización del medio margen era considerada como la proporción obligada para las misivas a Reyes, Príncipes y Señores de primera classe. ${ }^{19}$ Tan solo el $7 \%$ de las cartas reseñadas respetaron dicho medio margen, en concreto las remitidas por el maestro de la Real Capilla, Carlos Patiño, al cabildo dictaminando sobre un ejercicio de oposición [C 18] (Fig. 3); la carta del maestro de Sigüenza, Andrés de Viana [C 58]; la remitida por el maestro de Osuna, Diego José de Salazar [C 64]; también mantienen esta convención las enviadas por Miguel Mateo de Dallo, maestro de capiIla de la Imperial de Palacio de Logroño [C 65], la carta del chantre Crisóstomo Pérez [C 66] y la del maestro de capilla de Toledo, Pedro de Ardanaz [C 68], todas de una envidiable corrección formal; cabe añadir la carta de recomendación firmada por el organista de la Real Capilla de Carlos II,

\footnotetext{
18 Amor 2013: 1042. Véase Páez de Valenzuela 1630: 38.
}

19 ídem. 
FIGURA 3

Carta de Carlos Patiño al cabildo de la catedral de Cuenca

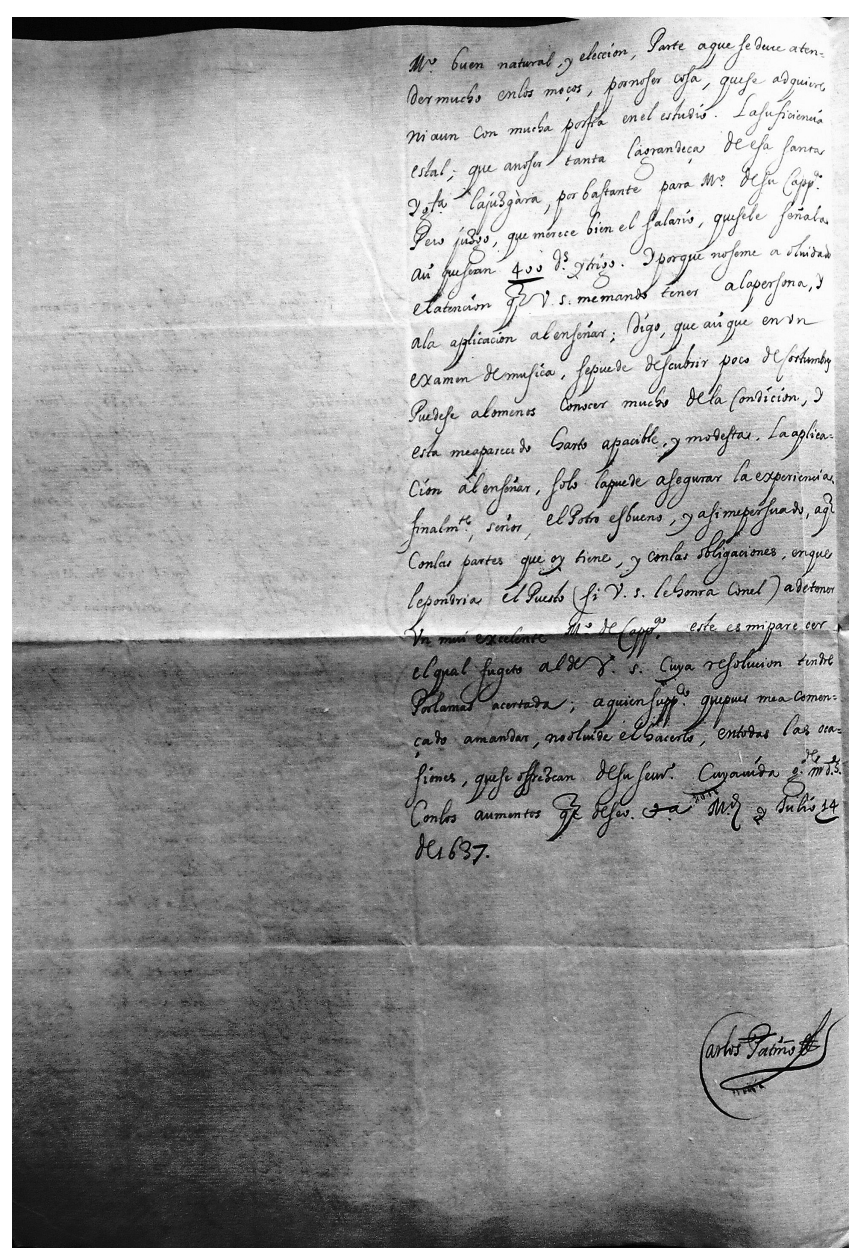

Doble folio a medio margen, se aprecia la huella del doblado. Verso de la carta [C 18]. Fuente: E-CU III 252/1 (73)

Sebastián Durón, en favor de su hermano Diego, maestro de capilla en Canarias [C 82].

El uso habitual era el mantenimiento del margen a un tercio [C 27], incluso, en menor medida, a un cuarto [C 69]. Dicha zona quedaba por tanto deshabilitada para recibir texto, aunque a veces era ocupada de forma longitudinal para finalizar y rematar la carta [C 28], aun a riesgo de que fuera entendida como una escritura descortés al no guardar la acostumbrada consideración hacia el destinatario. Muy rara vez hemos encontrado el texto centrado con doble margen izquierdo-derecho, aunque es frecuente también que el texto aparezca ubicado - centrado- ocupando la superficie entre el margen izquierdo, rodeado por un generoso espacio superior e inferior en blanco, como en los casos de las cartas del Presidente de Castilla y Arzobispo de Granada, don Fernando de Valdés y Llano [C 3] y la carta de agradecimiento del maestro de las Descalzas Reales, Tomás Micieces [C 55].

\subsection{Estructura}

Las fórmulas se mantienen casi invariables a lo largo del siglo XVII. No se aprecian modificaciones significativas de estilo, manteniéndose el uso humanístico anterior ya plenamente asimilado por los sectores sociales intermedios. Las fórmulas utilizadas en el corpus de referencia son paradigmáticas, uniendo la antigua práctica medieval con las nuevas tendencias en la formulación epistolar deferente Todo ello acude en favor del cumplimiento general de la sencillez y el equilibrio en la expresión frente al exceso y grandilocuencia que había proliferado en los escritos, convirtiéndolos en artificiosos y ocultando muchas veces bajo fórmulas de adulación el verdadero objeto de la misiva. ${ }^{20}$ Las constantes se pueden resumir con alguna pequeña variación en:

a) Encabezamiento (Inscriptio - salutatio), la fórmula suele ser muy sencilla y breve, exclusiva del tratamiento eclesiástico referenciada por Señor, Ilustrísimo Señor, Muy llustre señor y similares, siempre después de la invocatio crucis, en todo caso presidiendo la parte central superior del folio. A partir del primer tercio del Seiscientos se observa una paulatina desaparición de la fórmula de saludo, comenzando directamente el remitente por sus datos, nombre, oficio y a continuación abordar el asunto: «El maestro Andrés de Viana, natural y residente en esta ciudad de Sigüenza suplica a vuestra Señoría Ilustrísima sea servido de...» [C 58]; "Gabriel Pulpillo capellán de vuestra señoría digo..." [C 59]; "Joan Pacheco Montion maestro de capilla de esta santa iglesia de Plasencia y menor criado de Vuestra señoría beso a Vuestra señoría su mano y digo...» [C 70]; «Estimare vuestra señoría se halle con la salud que este su capellán desea...» [C 73]; "Pedro Redondo ministril corneta de esta santa iglesia catedral de Ciudad Rodrigo digo...» [C 79]; «Diez y seis años continuos he deseado lograr la fortuna de ser Maestro de Capilla de esa Sancta Yglesia...» [C 96].

En algunas ocasiones el comienzo adquiere un matiz más solemne, en función del cargo del remitente y de la jerarquía del destinatario eclesiástico. La manera de iniciar es similar a las fórmulas: "Holgaré infinito esta reciba vuestra merced con muy perfecta salud la cual rogaré al cielo la conserve muchos años en su gracia...» [C 60]; "Me alegrare halle ésta a vuestra merced con la salud que yo deseo, la mía es buena para servir a vuestra merced en todo lo que fuere servido de mandarme...» [C 64]; «En cumplimiento del mandato que a mi indignidad fue servido de imponer vuestra señoría he remitido...» [C 94]. Incluso utilizando un grado de barroquismo elevado: «Con el rendimiento del más humilde criado me pongo a los pies de vuestra señoría asegurado de su benigna clemencia no desdeñara los rendidos afectos con que venero a vuestra señoría y las veras con que mi deseo desea su mayor grandeza...» [C 92].

b) Cuerpo (narratio) es el lugar donde se exponen las circunstancias de la petición con fórmulas intermedias de tratamiento y recursos de elegancia propios de manual, aunque ya extendidos y al alcance de cualquiera por el uso, todas ellas de tipo formalista utilizadas para mantener la distancia y asimetría de los interlocutores y mostrar el remitente su consideración social, virtud y moralidad. Así encontramos un predominio claro de las fórmulas: "Señor», "Vuestra merced», "Vuestra Señoría», "Vuestra Señoría Ilustrísima», mantenidas independientemente del estatus social del remitente.

20 Aunque no es objeto de nuestro trabajo abordar el interesante estudio de la formulación y estética epistolar, citamos como ejemplo, entre otros muchos posibles, dos de los textos dedicados a la gente de pluma que fueron muy conocidos en la época como el de Páez de Valenzuela 1630 . 
Por otra parte, el contenido difiere entre unas y otras. En el caso musical la mayoría son solicitudes (petitio) de ingreso en los diferentes puestos vacantes, reclamaciones económicas, ofrecimiento de servicios, informes personales sobre cantores o maestros de capilla, incluso advertencias y consejos con urgencia de cumplimiento, o dictámenes sobre ejercicios de oposición. En todo caso, a pesar del abandono de la tradición retórica medieval, son frecuentes las figuras de humildad y captatio benevolentiae así como el uso abundante de la segunda persona de plural: vuestro, vuestra, os, decís, serviros, sepáis, veros, faltaros.

c) Remate (conclusio), fórmula de mayor variedad y extensión que el saludo en que se expresan los deseos de bienestar y felicidad al destinatario. Se suelen utilizar formas similares a las siguientes: "Guarde Dios a V.S. felicísimos años...» [C 1]; "Guarde Dios muchos años con los aumentos que deseo...» [C 2]; «Dios guarde vuestra señoría y prospere en la mayor grandeza...» [C 77]; "Guarde Dios a Vuestra Señoría para grandeza suya...» [C 32]; "Vuestra señoría Ilustrísima cuya vida guarde y prospere en su grandeza el cielo...» [C 54]; "Vuestra Señoría de cuya vida guarde Dios en la grandeza que ha menester...» [C 38]; "Me prometo criado de vuestra señoría llustrísima a quien nuestro señor prospere en su mayor grandeza...» [C 39]; «De quien me confieso criado más reconocido y como más obligado pido a Dios conserve la salud perfecta y en su mayor grandeza como sus criados deseamos...» [C 92].

d) Cierre, cómo fórmula final de cortesía prevalece la utilización de la retórica de humiliatio, tras ella la carta se firma y rubrica dando fin a esta: "Criado de vuestra merced...» [C 18]; "Criado de vuestra señoría...» [C 27]; "De vuestra señoría humilde capellán i siervo...» [C 26]; «Beso las manos de Vuestra Señoría Ilustrísima...» [C 29]; "Menor siervo de Vuestra llustrísima que su mano besa...» [C 67]. Cabe destacar que todas las cartas presentan datación completa, salvo tres de ellas en que aparece incompleta: C 73; C 74 y C 95.

\subsection{Sobrescrito}

Existe un uso diverso del "sobrescrito" ya que algunas de las cartas - las menos - lo contienen, en otras no hay nada y en el resto aparece una nota del secretario capitular especificando la fecha, el nombre remitente, el asunto

\section{FIGURA 4}

Sobrescrito sustituido por una nota del secretario capitular de la catedral de Cuenca

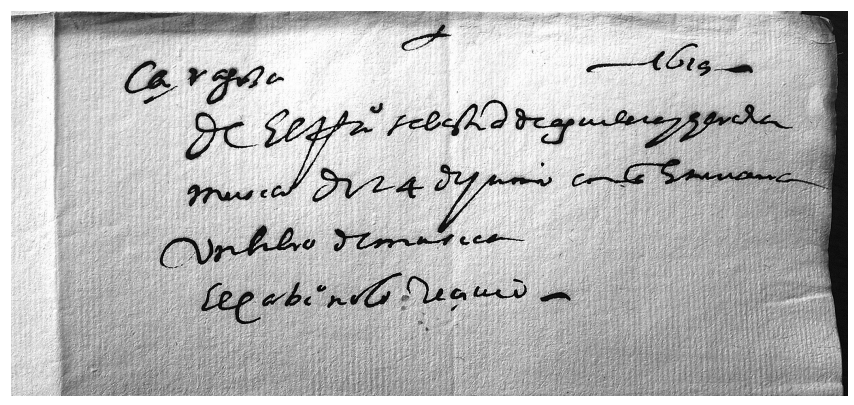

Verso de [C 1]: «çaragoza 1619 de el rao sebastian de aguilera y heredia musico de 24 de junio con questrenaua vn libro de musica El Cabio no lo reçiuio». Fuente: E-CU III. 244/2 (50) y la fecha de lectura en cabildo (Fig. 4), todas ellas sin huella de lacrado. En el caso de la aparición de sobrescritos de origen, el plegado dejaba ocultos los datos del remitente lo que significa que o bien las cartas fueron enviadas metidas en un sobre posiblemente desechado por el encargado del manejo de la correspondencia, o que llegaron por correo ordinario a pie.

\section{CONCLUSIONES}

La importancia de la información epistolar transciende al asunto en sí y desvela - casi en vivo- múltiples detalles sobre la expresión y carácter de estos músicos y, además, circunstancias poco frecuentes como la situación familiar, salud, pobreza o solvencia. A veces también son mencionados acontecimientos locales, problemas laborales, usos, maneras y costumbres del momento como también asuntos legales, rencillas internas, problemas de competencia, incluso choques escritos derivados de posicionamientos en causas políticas o económicas.

Aunque el número de cartas musicales finalmente reseñadas no ha sido demasiado elevado en relación con el volumen total de documentación revisada, la utilidad e interés del resultado para la época estudiada es indudable. Las cartas que mostramos aportan datos nuevos sobre cargos de política eclesial, compositores, cantores y ministriles, la mayoría nombres muy relevantes en su momento, a los que se añaden particularidades biográficas e históricas no mencionadas en los trabajos previos sobre la música catedralicia del siglo XVII: los datos invitan a considerar el estudio epistolar como un instrumento que invita a ser abordado desde otros puntos de vista, a la vez que abren nuevos caminos a la investigación musicológica.

Dada la extensión cronológica del estudio, no se descarta que puedan aparecer nuevos documentos relacionados en legajos no consultados hasta el momento. El autor entiende que el presente avance solo constituye un punto de partida inserto en un proyecto de recuperación patrimonial y documental de mayores dimensiones, quedando por tanto abierto a posibles ampliaciones.

\section{REGESTO DOCUMENTAL ${ }^{21}$}

[C 1]. Sebastián Aguilera y Heredia (Zaragoza) a cabildo (Cuenca)

E-CU III. 244/2 (50)

24-06-1619

El organista de la Seo de Zaragoza ofrece al cabildo un libro de Magnificat para el servicio del culto Divino. El libro fue informado negativamente por el maestro de capilla y no fue adquirido.

[C 2]. Pedro Zapata y Alonso del Pozo Palomino (Cuenca) a Vicente García (Valencia)

E-CU III. 250/1 (58)

10-09 1632

21 Los regestos han sido ajustados al siguiente modelo: [Carta número] Remitente (lugar) - Destinatario (lugar) / Signatura (según la tipología RISM) E-CU Sección. Legajo/carpeta (número de carta) / Fecha del documento / Regesto. 
El cabildo ofrece a Vicente García, maestro en la Seo de Valencia, el puesto de maestro de capilla por muerte de Juan de Castro, eximiéndole de la obligación de residencia y del mantenimiento de los seises: «solo le toca la enseñanza cada dia y hazer exerciçio publico vna ora a todos los infantes de coro y criados de la yglesia».

[C 3]. Fernando de Valdés y Llano (Granada) a deán y cabildo (Cuenca)

E-CU III. 250/2 (64)

08-11-1633

Carta del arzobispo Fernando de Valdés y Llano, Presidente de Castilla, en que ofrece al cabildo su disposición favorable a la incoación del expediente de la naturaleza del maestro de capilla: «y asi me he holgado de que saliese bien el despacho del maestro de capilla de vuestra señoria para que él se halle mas obligado al su seruiçio».

[C 4]. Claudio Pimentel (Madrid) a cabildo (Cuenca)

E-CU III. 250/2 (65)

09-11-1633

Informe de Claudio Pimentel sobre haber notificado al Presidente de Castilla el aumento de salario para el maestro de capilla (Vicente García).

[C 5]. Claudio Pimentel (Madrid) a cabildo (Cuenca)

E-CU III. 250/2 (68)

19-11-1633

El cabildo insta a Claudio Pimentel para que abogue ante el Gobernador de Castilla para dar carta de naturaleza castellana a Vicente García, maestro de capilla: «he comenzado a dar pasos en ella y aunque don Sebastian de Contreras me ha dificultado mucho el buen suceso por haberse negado casi lo mismo que pretendemos al Duque de ljar».

[C 6]. Claudio Pimentel (Madrid) a cabildo (Cuenca)

E-CU III. 250/2 (69)

\section{3-11-1633}

Claudio Pimentel informa del incremento de 300 ducados al maestro de capilla y la disposición de la media annata: «los trecientos ducados mas para el maestro de capilla han salido, con que ya tiene permision de seiscientos que es cantidad bastante, pienso que con la mas que vuestra señoria se ha seruido de hacerle».

[C 7]. Claudio Pimentel (Madrid) a cabildo (Cuenca)

E-CU III. 250/2 (70)

26-11-1633

Claudio Pimentel notifica la concesión de naturaleza al maestro de capilla con reducción de salario en 300 ducados: "Luego que reciuir la carta de vuestra señoria hable al señor gobernador de Castilla y señores consejeros de Camara [...] salio hoy el consentimiento que deseaba para el maestro de capilla, pero limitado para que solo pueda obtener 300 ducados de renta en ese obispado».

[C 8]. Juan de Quesada (Jaén) a cabildo (Cuenca)

E-CU III. 251/1 (18)

06-06-1634

El maestro de Jaén, Juan de Quesada, se ofrece por maestro de capilla y solicita del cabildo que remita un edicto a Jaén cuando saliere la oposición.
[C 9]. Salvador del Rey y Barroso (Málaga) a cabildo (Cuenca) E-CU III. 252/1 (28)

\section{4-03-1637}

Edicto de provisión del oficio de sochantre, impreso en que se solicita publicitarlo en las puertas de la catedral de Cuenca.

[C 10]. Martín Alonso (Córdoba) a cabildo (Cuenca)

E-CU III. 251/1 (78)

04-05-1637

Edicto de provisión impreso de una capellanía de cantor contrabajo anexa a la Capilla de San Acacio de la catedral de Córdoba por muerte de Alonso Bravo. La carta lleva una rúbrica manuscrita posterior (21-07-1637) del secretario: "esta Cappellania se proueio en Pedro de Ortega Matamoros contrauajo de Seuilla i no quiso uenir a seruirla i por su dexacion ua puesta la uacante en los editos».

[C 11]. Luis Julián (Orihuela) a cabildo (Cuenca)

E-CU III. 252/2 (44)

20-05-1637

Carta de respuesta de Luis Julián, maestro en Orihuela, a la orden del cabildo de Cuenca en que le convoca a Madrid para realizar los ejercicios de oposición teniendo como opositor al maestro de Teruel José de Rada: "Lo que suplico a vuestra señoria es pues yo hice oposicion de todo quanto es esencial para maestro de capilla que me ampare y pues hice villancico y motete mande vuestra señoria le vea cualquier maestro».

[C 12]. José de Rada (Teruel) a cabildo (Cuenca) E-CU III. 252/1 (46)

30-05-1637

José de Rada confirma en esta carta su asistencia el día 6 de julio a los ejercicios de provisión en Madrid teniendo por jueces a los maestros Mateo Romero y Carlos Patiño.

\section{[C 13]. Luis de Garay (Guadix) a Pedro de Alcalá (Cuenca) E-CU III. 252/1 (50) \\ 08-06-1637}

El maestro de Guadix, Luis de Garay, notifica y da poder a su primo en Cuenca, Pedro de Alcalá, para que comunique su presencia en la oposición a realizar en Madrid, si bien con algún retraso: «y será otro dia despues de la octaba del Corpus porque ahora es imposible poder dejar mi iglesia y asi suplico a vuestra merced me la haga de enseñar esta carta para que por ella vera como dandome Dios salud yre luego que pasen las fiestas».

[C 14]. Alonso de Olivares y Montemayor (Madrid) a cabildo (Cuenca)

E-CU III. 252/1 (53)

24-06-1637

Alonso de Olivares informe desde la Corte de Madrid al cabildo que Carlos Patiño y Mateo Romero no acudirán juntos a la oposición. El comisionado aconseja poner de compañero de Carlos Patiño a Gabriel Díaz (maestro de capilla de Córdoba) para realizar los exámenes en la capilla Real, una vez que el Rey hubiera regresado a la Corte tras finalizar el retiro que le mantenía ausente. 
[C 15]. José de Rada (Teruel) a cabildo (Cuenca)

E-CU III 252/1 (64)

05-07-1637

Solicitud del maestro de Teruel, José de Rada, al cabildo para que acelere la provisión al no poder atender los gastos que le ocasiona la espera en Madrid y dado que se le había agotado el permiso corría el riesgo de perderlo todo: «mire Vuestra señoria los gastos que en Madrid se ofrecen y con la pena que estoy de ver que cumpliendo con lo que Vuestra señoria me manda».

\section{[C 16]. Juan de Quesada (Jaén) a cabildo (Cuenca) \\ E-CU III 252/1 (66) \\ 07-07-1637}

Solicita permiso para hacer ejercicios para el magisterio de capilla: "y aunque mis cortos merecimientos no mereçen tan alto puesto, si Vuestra Señoria me da liçencia interviniendo su mandar iré a haçer demostración de mis humildes partes».

[C 17]. Diego José de Mata (Jaén) a cabildo (Cuenca)

E-CU III. 252/1 (68)

10-07-1637

Edicto de provisión al magisterio de capilla de la catedral de Jaén por muerte del maestro Juan de Riscos. El secretario solicita que sea fijado en la puerta de la catedral y que le sea remitido testimonio de ello.

\section{[C 18]. Carlos Patiño (Madrid) a cabildo (Cuenca) \\ E-CU III 252/1 (73) \\ 14-07-1637}

Dictamen del maestro de la Real capilla, Carlos Patiño, sobre la oposición a la que solo se presentó José de Rada. El proceso duró cinco días (del 9 al 13 de julio) y el maestro fue juzgado como suficiente: «señor el potro es bueno, y asi me persuado a que con las partes que hoy tiene, y con las obligaciones que le pondria el puesto (si vuestra señoria le honra con el) ha de tener un muy excelente maestro de capilla».

[C 19]. Fray Diego Ruiz de Peralta (Convento de San Felipe, Madrid) a cabildo (Cuenca)

E-CU III 252/1 (80)

25-07-1637

Se notifica al cabildo desde el convento de San Felipe de Madrid la enfermedad mortal de José de Rada, solicitando ayuda para su entierro «a mi como deudo suyo y persona que mas le toca me habia pedido que la estafeta pasada escribiera a Vuestra Señoria suplicando se apiadase y conpadeciese de los gastos que el dicho maestro ha hecho».

[C 20]. Luis de Garay (Guadix) a cabildo (Cuenca)

E-CU III. 252/1 (83)

03-08-1637

El maestro de Guadix, Luis de Garay, disculpa entre el cabildo el haberle sido imposible acudir al examen anterior por impedirlo la guardia real a los provenientes del reino de Granada. Solicita, dada la persistencia de la vacante, acudir a hacer oposición a Madrid: «si Vuestra Señoria me da liçençia que después de Nuestra Señora de septiembre parezca a ser examinado en esa çiudad o en Madrid».
[C 21]. Juan de Quesada (Jaén) a cabildo (Cuenca)

E-CU III. 252/1 (84)

04-08-1637

El maestro de Jaén, Juan de Quesada, notifica al cabildo que no podrá asistir a los ejercicios del magisterio si no se dilatan los edictos, dada la coincidencia de fechas de la oposición de Cuenca y Jaén: «donde me es fuerça asistir a ser opositor, que a no ser ansi fuera a besar los pies a ese llustrisimo cauildo a agradeçer el fauor y merced que he reçevido».

[C 22]. Fray Diego Ruiz de Peralta (Madrid) a cabildo (Cuenca) E-CU III. 252/1 (81)

05-08-1637

Fray Diego Ruiz notifica al cabildo la muerte del maestro de Teruel, José de Rada, y solicita la ayuda previamente concedida para el entierro y para auxiliar la necesidad de la madre: «no digo la neçesidad tan extrema que padece la madre del difunto que es ynfinita lo que en todo esto quiero suplicar a vuestra señoria es que se sirba de mandar al señor don Fernando execute la libranza que vuestra señoria ya dio».

[C 23]. Luis de Garay (Guadix) a cabildo (Cuenca)

E-CU III. 252/1 (88)

10-08-1637

Luis de Garay informa al cabildo de haber obtenido licencia de su iglesia para opositar a primeros de octubre. Garay dice conocer a Juan Quesada: «es ministril de aquella santa iglesia y verdaderamente sabe».

[C 24]. Juan de Quesada (Jaén) a cabildo (Cuenca)

E-CU III. 252/1 (91)

10-08-1637

Juan de Quesada agradece al cabildo el haberle permitido opositar en Jaén y Cuenca, y solicita ser avisado de las fechas de los ejercicios, ofreciéndose estar en caso de ser recibido dos años a prueba en el magisterio.

[C 25]. Antonio de Salinas (Madrid) a Claudio Pimentel (Cuenca)

E-CU III. 252/1 (93)

02-09-1637

El ministril Antonio de Salinas solicita la plaza de corneta en la catedral de Cuenca donde ya se encontraba su hermano, Ignacio de Salinas, del cual manifiesta abiertamente su distanciamiento: «se me haga merced de darme la plaça de ministril y corneta supuesto que mis partes y condicion es diferente que la de Ignaçio de Salinas que aunque somos hermanos no lo somos en los hechos».

\section{[C 26]. Diego de Gastea (Granada) a cabildo (Cuenca)}

E-CU III. 252/1 (99)

15-09-1637

Solicitud del secretario capitular de la catedral de Granada para publicar un edicto de provisión de tiple: "suplico a vuestra merced se sirua de mandar que se fije a las puertas de esa santa iglesia donde es costumbre».

[C 27]. Francisco Correa (Jaén) al secretario del cabildo (Cuenca)

E-CU III. 252/1 (100)

15-09-1637 
Misiva dirigida al secretario capitular, Alonso López de Soria, para que haga llegar al comisario de música (Alonso del Pozo) una carta de recomendación detallada a favor del candidato a maestro de capilla, Juan de Quesada

\section{[C 28]. Francisco Correa (Jaén) a Alonso del Pozo (Cuenca) E-CU III. 252/1 (101) \\ 15-09-1637}

El organista Francisco Correa relata que aunque el cabildo conquense había ofrecido el puesto de maestro de capilla a Juan de León, maestro en Segovia, y que este había resuelto quedarse, y dado que él estaba muy agradecido por haberle sido ofrecida la plaza de Peraza que finalmente no pudo servir la plaza por falta de salud cuando estaba en la colegial de San Salvador de Sevilla, recomienda a Juan de Quesada como maestro de capilla: «informese vuestra merced en Madrid, Toledo, Seuilla, Cordoba, Granada, Malaga y en toda España quien es Francisco Correa organista de Jaen».

[C 29]. Fray Cristóbal Rubio (Convento de Santo Domingo, Sevilla) a cabildo (Cuenca)

E-CU III. 252/1 (122)

24-09-1637

Carta del poderdante de Manuel de Tavares, fray Cristóbal Rubio, maestro de capilla y alumno de Manuel de Tavares donde expresa la voluntad de Tavares de regresar a cualquiera de las iglesias de la Península, abogando y ofreciéndose por maestro de capilla de Cuenca por ser «uno de los mayores y más consumados maestros que hoy tiene la música».

[C 30]. Antonio de Salinas (Madrid) a cabildo (Cuenca) E-CU III. 252/1 (123)

\section{2-12-1637}

Respuesta de Antonio de Salinas a la notificación del cabildo de 9 de diciembre. En la presente el ministril acepta el puesto de corneta en la catedral de Cuenca lamentándose del escaso salario asignado.

[C 31]. Baltasar de la Cueva (Cuenca) a cabildo (Cuenca) E-CU III. 253/1 (59)

09-08-1640

Carta del cantor Baltasar de la Cueva en que se despide del cabildo por haber sido recibido en la catedral de Córdoba en una capellanía de tiple con 700 ducados de renta.

[C 32]. José Setimio (Cuenca) a cabildo (Cuenca)

E-CU III. 253/1 (64)

22-08-1640

Carta José Setimio (ministril corneta) en que se despide por haber sido recibido en la catedral de Sevilla, y ofrece como sustituto a Bautista Camirlo, ministril en la catedral de Valencia y discípulo suyo.

[C 33]. Vicente García (Madrid) a cabildo (Cuenca)

E-CU III. 253/1 (85)

20-10-1640

Carta de recomendación del maestro de capilla Vicente García ante la ida a Sevilla de José Setimio. García recomienda al toledano José de Arce, discípulo de Juan de
Lozoya, como nuevo ministril corneta «con muy buen tono» que era también diestro con la chirimía, para tañer versos al órgano, y como cantor y contrapuntante; queda a la espera de noticias para ir a Cuenca a ser oído por el cabildo.

[C 34]. Juan de Lozoya (Toledo) a cabildo (Cuenca)

E-CU III. 253/1 (86)

30-10-1640

Carta del ministril de la catedral de Toledo, Juan de Lozoya, en que reitera el ofrecimiento de su discípulo [José de Arce] para que se desplace a Cuenca para ser examinado; en la carta también ofrece él mismo sus servicios al cabildo.

\section{[C 35]. Juan Piñero (Madrid) a cabildo (Cuenca)}

E-CU III. 253/1 (96)

\section{7-12-1640}

Informe del comisario Juan Piñero al cabildo en que dice haber examinado a José de Arce en Madrid y cómo a pesar del dictamen favorable del maestro Vicente García aconseja que vaya a hacer pruebas a Cuenca para poder ajustar su salario.

[C 36]. Diego de Mata, y otros (Cuenca) a Juan de Soria Quiñones (Cuenca)

E-CU III. 253/3 (16)

\section{2-07-1642}

Solicitud por parte de los ministriles de la capilla conquense, Diego de Mata, Miguel de Campos, Juan Escudero, José de Arce, y Pedro de Celaya, para que les fueran abonados 10 ducados de salario por haber intervenido de forma extraordinaria en la llegada del rey a Cuenca.

[C 37]. Juan Felipe Ilzarbe (Granada) a deán y cabildo (Cuenca)

E-CU III. 260/1 (22)

05-07-1661

Carta del sochantre de Granada, Juan Felipe Ilzarbe, y que ofrecimiento de servicios solicita una ayuda de costa de cien ducados para ir a ser oído: "y aseguro a Vuestra Señoria que se ha de holgar de oirme y que no ha de hallar en toda Castilla ni en la Andalucia sochantre tan general en todo genero de cantar y en haçer el oficio».

[C 38]. Juan Felipe Ilzarbe (Granada) a cabildo (Cuenca) E-CU III. 260/1 (27)

09-08-1661

Carta en que comunica al cabildo que hay personas (no referenciadas) que obstaculizan e impiden recibir la ayuda de costa necesaria para poder desplazarse hasta Cuenca para ser oído: «asegurando que aunque me den cuando pida licencia, como puede ser, algun aumento pequeño o grande lo dejare todo por estar tan afiçionado a Vuestra Señoria».

[C 39]. José de Alcalá (Cuenca) a Diego de Sandoval Pacheco (Cuenca)

E-CU III. 260/2 (2)

04-01-1662

El maestro de capilla de la catedral de Cuenca, José de Alcalá, informa al cabildo de la amenaza de cárcel sufrida por haber obedecido al deán y haber cantado un villancico que había prohibido el provisor. 
[C 40]. Gaspar de Alvarado (Consejo de Castilla, Madrid) a cabildo (Cuenca)

E-CU III. 260/2 (3)

19-01-1662

Carta desde la Corte sobre el conflicto del villancico en el que Gaspar de Alvarado solicita que le sean dadas instrucciones y remitidos los villancicos para que el Presidente de Castilla dictamine al respecto: «y de cómo su llustrisima a dicho a un gran ministro que los villancicos son malsonantes y satíricos».

[C 41]. Gaspar de Alvarado (Madrid) a cabildo (Cuenca) E-CU III. 260/2 (8)

28-01-1662

Respuesta de Gaspar de Alvarado a la misiva del cabildo de día 25 de enero sobre el porqué no se había obrado judicialmente en lo referente a los villancicos: "el hablar en ellos ha sido en orden a dar a entender extrajudiçialmente a quien me lo motiuó el que el villançico impreso fue el que se cantó en orden del Dean y no el otro, y que este nunca se boluió a cantar como es çierto y consta».

[C 42]. Gregorio de Salinas (Ciudad Rodrigo) a cabildo (Cuenca)

E-CU III. 260/3 (39)

22-10-1663

Carta de ofrecimiento del maestro de capilla de Ciudad Rodrigo, Gregorio de Salina, para cubrir la vacante de Cuenca y hacer los villancicos de la Navidad. En la misma dice que fue educado en la Corte de Madrid y solicita al cabildo que se informe sobre su suficiencia de Carlos Patiño y Juan Pérez Roldán; en su escrito afirma haber sido rector del colegio de infantes de coro de Burgos. El cabildo acordó suspender la resolución ya que estaba pendiente la promulgación del edicto de oposición.

[C 43]. Miguel Zamorano (Teruel) a cabildo (Cuenca)

E-CU III. 260/3 (41)

04-11-1663

Carta del sochantre Miguel Zamorano, ofreciéndose para ser oído: «lo que me anima a ir es que el día de todos santos canté un verso que se holgó mucho el maestro Alcalá [José de Alcalá] que ha uenido desa santa yglesia y me ha dicho puedo pretender muy bien porque gloria a Dios tengo un pedazo de boz harto considerable [...] son deziseis puntos de boz».

[C 44]. Gregorio de Salinas (Ciudad Rodrigo) a cabildo (Cuenca)

E-CU III. 260/3 (41)

12-11-1663

Carta en que el maestro Gregorio de Salinas informa al secretario del cabildo, Luis maestro Caxa, que será opositor al magisterio de Cuenca. A su vez refiere el inconveniente de las oposiciones por los grandes gastos que ocasionan poniendo como ejemplo la catedral de Toledo, y el nombramiento mediante informes del maestro Juan de Padilla.

[C 45]. Francisco de Bustamante y Gemio (Segovia) a Tomás de Micieces (Madrid)

E-CU III. 260/4 (32)

30-07-1664

Carta personal del deán de la catedral de Segovia al maestro Tomás de Micieces en la que le informa de la decisión de prórroga respecto a los edictos de provisión del magisterio segoviano.

El reverso contiene el borrador de una carta de Tomás de Micieces dirigida al Obispo de Segovia.

[C 46]. Diego Escolano y Ledesma (Segovia) a Tomás de Micieces (Madrid)

E-CU III. 260/4 (39)

14-08-1664

Resolución del Obispo de Segovia, Diego Escolano, en la que rechaza la reprobación hecha por Tomás Micieces al maestro Juan Pérez Roldán, juez para la provisión del magisterio de Segovia, en virtud de que: «estas son cosas tocantes a los cabildos no pueden los Prelados obrar como en otros negocios». La causa fue que Roldán había desacreditado de forma injustificada a su discípulo y opositor, Alonso Xuárez.

[C 47]. Francisco de Bustamante y Gemio (Segovia) a Tomás de Micieces (Madrid)

E-CU III. 260/4 (40)

14-08-1664

Notificación del deán de la catedral de Segovia, Francisco de Bustamante, sobre la decisión del cabildo de apoyar la actuación del maestro Juan Pérez Roldán.

[C 48]. Diego Antonio de Sandoval Pacheco (Madrid) a cabildo (Cuenca)

E-CU III. 260/4 (42)

16-08-1664

El chantre, comisionado en Madrid, aporta información al cabildo sobre el maestro de capilla de Sigüenza, Alonso de Torices: "Este sujeto me insinuó diversas veçes que ofreciendose ocasión iría a Cuenca por la autoridad y gravedad de esa Yglesia».

[C 49]. Diego Antonio de Sandoval Pacheco (Madrid) a cabildo (Cuenca)

E-CU III. 260/4 (44)

20-08-1664

Informe del chantre Diego A. de Sandoval al cabildo sobre los incidentes sufridos por Alonso Xuárez en la oposición de Segovia, recomendando de Gregorio Salinas para maestro de capilla de la catedral de Cuenca.

[C 50]. Diego Antonio de Sandoval Pacheco (Madrid) a cabildo (Cuenca)

E-CU III. 260/4 (45)

23-08-1664

Informe del comisionado capitular sobre el estado de la causa sobre la provisión de maestro de capilla.

[C 51]. Tomás Micieces (Madrid) a cabildo (Cuenca)

E-CU III. 260/4 (41)

23-08-1664

Carta de Tomás Micieces a favor del aspirante al magisterio, Alonso Xuárez.

[C 52]. Diego Antonio de Sandoval Pacheco (Madrid) a cabildo (Cuenca)

E-CU III. 260/4 (46)

27-08-1664 
Informe del comisario capitular sobre el aspirante al magisterio conquense, Gregorio Salinas, detallando su comportamiento cuando estuvo a cargo del colegio de los seises de Burgos.

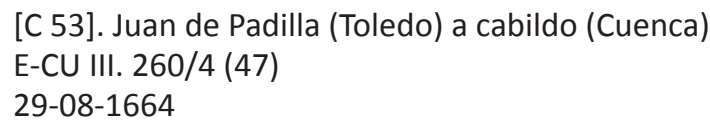

Informe sobre Alonso Xuárez: «discipulo del maestro Thomas Micieces, es en sus estudios y su virtud tan conveniente para ese puesto que quedo yo mui agradecido a la ocasión de dar a esa santa iglesia una prenda».

[C 54]. Diego Antonio de Sandoval Pacheco (Madrid) a cabildo (Cuenca)

E-CU III. 260/4 (48)

30-08-1664

Informe y recomendación del chantre a favor de Gregorio Salinas para maestro de capilla.

[C 55]. Tomás Micieces (Madrid) a cabildo (Cuenca)

E-CU III. 260/4 (51)

6-09-1664

Carta de agradecimiento del maestro Tomás Micieces por el recibimiento de su discípulo Alonso Xuárez por maestro de capilla en Cuenca.

[C 56]. Diego Antonio de Sandoval Pacheco (Madrid) a cabildo (Cuenca)

E-CU III. 260/4 (52)

6-09-1664

Queja desde la Corte del chantre, Antonio de Sandoval, por no haber tenido en cuenta sus recomendaciones sobre el nombramiento de maestro de capilla.

[C 57]. Juan de Padilla (Toledo) a cabildo (Cuenca)

E-CU III. 260/4 (54)

12-09-1664

El maestro de capilla de la catedral de Toledo, Juan de Padilla agradece al cabildo por haber considerado su informe referente a Alonso Xuárez como maestro de capilla.

[C 58]. Andrés de Viana (Sigüenza) a cabildo (Cuenca) E-CU III. 260/4 (55)

20-09-1664

El maestro de capilla Andrés de Viana «natural y residente de la ciudad de Sigüenza» solicita ser admitido como maestro de capilla en Cuenca.

\section{[C 59]. Gabriel Pulpillo (Cuenca) a cabildo (Cuenca)}

E-CU III. 261/2 (16)

23-04-1667

El capellán Gabriel Pulpillo solicita aumento de salario por tener necesidad para mantener a sus hermanos y sobrinos, tras haber estado 16 años como sochantre teniendo asistencia de día y de noche, el cargo de los infantes de coro, encomendar las capas, además de 52 misas. El cabildo le da una ayuda de costa de 500 reales.

[C 60]. José de Villanueva (Plasencia) a cabildo (Cuenca)

E-CU III. 261/4 (44)

20-10-1669
El sochantre principal de los cuatro que había en la catedral de Plasencia, licenciado José de Villanueva, manifiesta al cabildo de Cuenca su ofrecimiento para servir la plaza de sochantre.

[C 61]. Francisco Navarro (Murcia) a cabildo (Cuenca)

E-CU III. 261/4 (49)

9-12-1669

El teniente de sochantre de la catedral de Murcia, Francisco Navarro, teniendo noticia de la necesidad de sochantre o salmista en la catedral de Cuenca solicita que asegurándole la ayuda para su camino irá a ser oído: «porque cada día estamos con la muerte a la vista porque el rio a estado muy cerca de anegarnos muy pocos días haçe».

[C 62]. Pedro Muro y Ochoa (Mirabueno, Guadalajara) a cabildo (Cuenca)

E-CU III. 262/2 (37)

11-06-1671

El sochantre de Sigüenza, Pedro Muro, refiere al cabildo la conversación mantenida con el maestro Alonso Xuárez y manifiesta su disposición de servir en Cuenca por 500 ducados al año una vez pasada la fiesta de Santa Librada.

[C 63]. José de Villanueva (Plasencia) a cabildo (Cuenca)

E-CU III. 262/3 (61)

7-05-1672

El sochantre de Plasencia reitera su deseo y causas principales por las que solicita ser oído en Cuenca al no haber obtenido respuesta.

[C 64]. Diego José de Salazar (Osuna) a cabildo (Cuenca)

E-CU III. 263/2 (43)

25-08-1675

El maestro de Osuna, Diego José de Salazar, se ofrece a ir a opositar a Cuenca por haber vacado el magisterio por la marcha de Alonso Xuárez a la catedral de Sevilla.

[C 65]. Miguel Mateo de Dallo (Logroño) a cabildo (Cuenca) E-CU III. 263/2 (67)

19-10-1675

El maestro de capilla de la Imperial del Palacio de Logroño, Miguel Mateo de Dallo, manifiesta al cabildo de Cuenca su deseo de optar al magisterio, para lo cual envía "unas miserables obras» entre las que incluye una misa, cinco villancicos de Navidad y dos al Santísimo.

[C 66]. Crisóstomo Pérez (Alcalá de Henares) a cabildo (Cuenca) E-CU III. 263/2 (81)

3-12-1675

El chantre de la iglesia magistral de Alcalá, el doctor Crisóstomo Pérez agradece al cabildo su ayuda y le ofrece su servicio.

[C 67]. Miguel Mateo de Dallo (Logroño) a cabildo (Cuenca) E-CU III. 263/3 (39)

16-11-1676

El maestro Mateo de Dallo agradece al cabildo que se vayan a cantar los villancicos en la Navidad, ofreciendo enviar más composiciones: "me anima el considerar que cantandolos y regiendolos vna capilla tan realzada como es la de vuestra señoria pareceran bien». 
[C 68]. Pedro de Ardanaz (Toledo) a cabildo (Cuenca)

E-CU III. 263/4 (52)

27-07-1677

Pedro de Ardanaz, maestro de capilla en la catedral de Toledo, escribe una carta de recomendación a favor de su discípulo, Mateo de Dallo: «es sacerdote, mui buen latino [...] mui estudioso: por cuyas razones suplico a vuestra señoria se sirba de dignarse auisarme si gusta de reçiuirle».

[C 69]. Raimundo Melchor y Miralles (Roma) a cabildo (Cuenca)

E-CU III. 266/4 (44) [Ocupa un orden posterior en un legajo posterior]

19-10-1681

Respuesta del comisionado en Roma al cabildo sobre el mandato para iniciar las diligencias a favor de obtener de Su Santidad una media ración a favor del maestro Alonso Xuárez.

[C 70]. Juan Pacheco Montion (Plasencia) a cabildo (Cuenca) E-CU III 265/4 (4)

13-03-1683

El que fue maestro de capilla en la catedral de Coria, Juan Pacheco, sobrino y discípulo de Juan de Padilla, informa al cabildo de hallarse con la graduación suficiente en su facultad como maestro de capilla en Plasencia, y solicita ser admitido por maestro en Cuenca.

[C 71]. Sebastián de Peralta y Montesa (Madrid) a cabildo (Cuenca)

E-CU III 265/4 (18)

5-07-1683

Sebastián de Peralta, librero se ofrece para hacer libros en pergamino para el coro: «que en Madrid hice todos los libros de San Isidro y en las mejores Iglesias de España».

[C 72]. Alonso Xuárez (Sevilla) a cabildo (Cuenca)

E-CU III. 265/4 (39)

6-09-1683

Carta de aceptación del magisterio de capilla por parte de Alonso Xuárez en la que agradece al cabildo de Cuenca haber promovido su regreso y manifiesta su deseo de ponerse en camino en el momento en que la enfermedad se lo permita.

[C 73]. Juan Guerrero (Valencia) a cabildo (Cuenca)

E-CU III. 265/4 (64)

24-(sin mes)-1683

El sochantre del Real Colegio del Patriarca, Juan Guerrero, manifiesta haber tenido noticias de Alonso Xuárez de encontrarse el puesto disponible en Cuenca y solicita ser admitido en el mismo.

[C 74]. Julián de Castro (Sevilla) a cabildo (Cuenca)

E-CU III. 265/4 (65)

(sin fecha)-1683

El racionero de la catedral de Sevilla, Julián de Castro, se ofrece al cabildo de Cuenca como cantor tiple mediando informe del maestro Alonso Xuárez.

[C 75]. Juan Guerrero (Madrid) a cabildo (Cuenca)

E-CU III. 266/4 (32)

2-04-1687
El capellán y sochantre de la colegial de Alcalá de Henares solicita ser avisado con la mayor brevedad sobre la posibilidad de ser admitido en Cuenca, siendo avisado e informado el cabildo por Juan Matías de Viana, maestro de capilla de las Reales Descalzas de Madrid.

\section{[C 76]. Giuseppe Sacripanti (Roma) a cabildo (Cuenca) E-CU III. 266/4 (43) \\ 18-10-1687}

Informe sobre la negociación llevada a cabo en Roma sobre la media ración de Alonso Xuárez: "A misura della sima fo'delle $\mathrm{S}^{\text {rie }}$ VV. Illme hauro'nesi li reguardi posibili in proposito della pretencione del signore Don Alonso Juares conforme lo significato al signore Agente di gia ne ho parlato a Mons ${ }^{\text {re }}$ Batanco».

[C 77]. Giuseppe Sacripanti (Roma) a cabildo (Cuenca)

E-CU III. 266/4 (40)

12-[12]-1687

Información del cardenal "buccino» sobre el trámite de la ración de Alonso Xuárez: "Cio conuiene anco a'gli interesi delle Srie de quali $D$. Valentino sara ben instrutto, et io obligato ad asistergli con ogni affetto ounque bisogni, e zertero tenuto alle Srie particularmente del fauore».

[C 78]. Juan Guerrero (Madrid) a cabildo (Cuenca)

E-CU III. 267/2 (41)

6-08-1689

El sochantre Juan Guerrero solicita al cabildo ser dado por opuesto a la sochantría de Cuenca: «atendiendo a que he sido sochantre racionero de la santa iglesia de Avila lo qual me conoce el señor don Antonio Aracil que entiendo esta en esa santa yglesia», recientemente recibido en la de Plasencia.

[C 79]. Pedro Redondo (Ciudad Rodrigo) a cabildo (Cuenca) E-CU III. 267/2 (51)

6-10-1689

El ministril corneta de Ciudad Rodrigo, Pedro Redondo, solicita ser informado en caso de que sean promulgados edictos de oposición.

[C 80]. José Martínez Clavero (Madrid) a cabildo (Cuenca) E-CU III.268/3 (3)

22-01-1695

El sochantre de Cuenca que servía en la fecha en la Encarnación de Madrid, José Martínez, solicita el pago de 60 ducados que le debía la Iglesia: «por considerar que suena muy mal en los tribunales no pagan los señores canonigos y mas siendo de esa santa yglesia».

[C 81]. Juan de Alcaraz (Valencia) a cabildo (Cuenca)

E-CU III. 268/3 (38)

16-06-1695

El sochantre Juan de Alcaraz se disculpa por no haber podido acudir a la oposición al cumplimiento de los edictos por no haber conseguido licencia y solicita poder acudir en caso de mantenerse todavía la plaza disponible.

[C 82]. Sebastián Durón (Madrid) a cabildo (Cuenca)

E-CU III. 268/4 (19)

4-07-1696 
Carta de recomendación de Sebastián Durón en favor de su hermano Diego Durón, maestro de capilla en Canarias: "se yo evidentemente que haciendole vuestra señoria la honrra de hazer en él el nombramiento lo dejara todo por lograr esa fortuna pues expresamente me ha escrito algunas veces que solo a la de Cuenca vendria».

[C 83]. Matías Navarro (Orihuela) a cabildo (Cuenca)

E-CU III. 268/4 (24)

24-07-1696

El maestro de capilla de Orihuela, Matías Navarro, solicita al cabildo ser recibido por maestro en Cuenca: "para cuya execucion solo espero orden de vuestra señoria ilustrisima la qual executare incontinente desocupandome de la obligación de esta santa yglesia cathedral».

[C 84]. Crisanto Jacinto de Escobar (Teruel) a cabildo (Cuenca)

E-CU III. 268/4 (29)

18-08-1696

El maestro de Teruel, Crisanto Jacinto de Escobar, solicita ser recibido por maestro: "y en este vuelvo a molestar a vuestra señoria remitiendo esos malos borrones para que vuestra señoria los mande probar y por ellos se reconocera mi corta habilidad».

[C 85]. Sebastián Durón (Madrid) a cabildo (Cuenca) E-CU III. 268/4 (30)

\section{2-08-1696}

Comunica al cabildo que al saber que su hermano Diego no sería recibido por estar en negociaciones con Tomás Juan de Viana: "respecto de esto me es preciso decir a vuestra señoria como ni mi hermano vendrá ni yo por él pretendo más que la honra de aspirar a muchas ordenes del agrado de vuestra señoria».

[C 86]. Crisanto Jacinto de Escobar (Teruel) a Pedro Balthanas (Cuenca)

E-CU III. 268/4 (31)

25-08-1696

El maestro de Teruel comunica al cabildo el envío de villancicos para que el deán requiera los informes necesarios para la admisión al magisterio de Cuenca.

[C 87]. Crisanto Jacinto de Escobar (Teruel) a Pedro Balthanas (Cuenca)

E-CU III. 268/4 (32)

1-09-1696

Pide que se le entregue al cabildo un laudate olvidado: «remitolo para que vuestra merced lo entregue a esos señores para que se juzgue tambien de las obras de latin y no sea todo romance».

[C 88]. Juan Montero del Villar y Figueroa (Pastrana) a cabildo (Cuenca)

E-CU III. 268/4 (34)

25-08-1696

El maestro de la colegial de Pastrana, Juan Montero del Villar y Figueroa manifiesta al cabildo su deseo de servir por maestro de capilla, siendo examinado para ello.
[C 89]. Juan de la Blanca (Madrid) a cabildo (Cuenca) E-CU III. 268/4 (35)

\section{9-08-1696}

El licenciado Juan de la Blanca recomienda al cabildo a Roque Lázaro para ser tomado por maestro de capilla en la vacante de Alonso Xuárez.

[C 90]. Juan Miguel de Chalecu (Madrid) a cabildo (Cuenca) E-CU III. 268/4 (36)

29-08-1696

Juan Miguel de Chalecu, antiguo infante de coro de la catedral de Cuenca y ahora cantor en las Descalzas, recomienda al cabildo a Roque Lázaro: «mozo de toda habilidad el qual irá a ser examinado si vuestra señoria gustare, tiene hecha vna oposición a la cathedral de Osma a donde perdió por la edad y no por la insuficiencia».

[C 91]. Roque de Lázaro (Madrid) a cabildo (Cuenca) E-CU III. 268/4 (37)

29-08-1696

Roque de Lázaro solicita ser examinado por maestro de capilla al haberse enterado que Antonio de Literes no había correspondido a la llamada del cabildo.

[C 92]. Julián Martínez Díaz (Jerez) a cabildo (Cuenca)

E-CU III. 268/4 (42)

30-09-1696

El discípulo de Alonso Xuárez y maestro de capilla de la catedral de Jerez, Julián Martínez Díaz, envía al cabildo algunas obras para la fiesta de Navidad.

[C 93]. Julián Martínez Díaz (Jerez) a cabildo (Cuenca)

E-CU III. 268/4 (51)

28-10-1696

El maestro de capilla Julián Martínez Díaz agradece al cabildo de Cuenca haber aceptado sus composiciones para ser presentadas en Navidad.

[C 94.] Julián Martínez Díaz (Jerez) a cabildo (Cuenca)

E-CU III. 268/4 (59)

16-12-1696

Julián Martínez Díaz notifica al cabildo el envío de las obras escritas para la fiesta de Navidad: «en cumplimiento del mandato que a mi indignidad fue seruido de imponer vuestra señoria he remitido la composición de los villancicos que he compuesto para las Pascuas».

[C 95]. Crisanto Jacinto de Escobar (Teruel) a cabildo (Cuenca) E-CU III. 268/4 (66)

[Sin fecha, por el contenido cabe inferir que se trate de la primera de la serie, a pesar del orden en que aparece en el legajo].

El maestro de capilla de Teruel, Crisanto Jacinto de Escobar, se ofrece al cabildo conquense por maestro de capilla de la catedral.

[C 96]. Matías Durango (Santo Domingo de la Calzada) a cabildo (Cuenca)

E-CU III. 269/1 (1)

9-01-1697

Matías Durango, maestro en Santo Domingo de la Calzada (La Rioja) solicita ser maestro de capilla en Cuenca. 


\section{FUENTES}

Chacón Gómez-Monedero, Francisco A. 2001. Guía del Archivo de la Catedral de Cuenca. Cuenca: Delegación de Medios. Obispado de Cuenca.

Ezpeleta y Mallol, Gaspar de. 1714. Practica de secretarios: que contiene una concisa explicacion de las calidades de este empleo, distincion de las cartas misivas, y declaracion de las circunstancias principales de que deben constar para tenerse por bien escritas. Madrid: Imprenta de Francisco Antonio de Villa-Diego.

Martínez Catalán, Ángel. 2019. Inventario de la Sección «Sede vacante» del Archivo de la Catedral de Cuenca. Cuenca: Cabildo de la Catedral de Cuenca y Asociación Seminario de Cultura Lope de Barrientos.

Páez de Valenzuela y Castillejo, Juan. 1630. Nuevo estilo y formulario de escrivir cartas missivas, y responder a ellas en todos generos, $y$ especies de correspondencia à lo moderno. Córdoba: S. de Cea Tesa.

Tesauro, Emanuele. 1696. Arte de cartas misivas, o Methodo general para redvcir al papel quantas materias pide el politico comercio. Valencia: Jaime de Bordazar.

\section{BiBLIOGRAFÍA}

Amor López, Silvia. 2013. "Las vías de análisis de la correspondencia: las cartas de los Aparici (siglo XVIII)». En De la tierra al cielo. Líneas recientes de investigación en Historia Moderna, 1037-1054. Zaragoza: Institución Fernando el Católico.
Caballero Fernández-Rufete, Carmelo. 1990. «Miguel Gómez Camargo: correspondencia inédita». Anuario Musical 65: 67-102.

Escrivá Llorca, Ferrán. 2013. «La vida en las Descalzas Reales a través de los epistolarios de Juan de Borja (1584-1604)». En Tomás Luis de Victoria. Estudios, editado por Javier Suárez Pajares y Manuel del Sol, 437-452. Madrid: Instituto Complutense de Ciencias Musicales.

Fuente Charfolé, José Luis de la. 2013. Música policoral de la Catedral de Cuenca. Motetes al Señor y los Santos de Alonso Xuárez (16401696). Madrid: Editorial Alpuerto.

Fuente Charfolé, José Luis de la. 2019. La música en la Catedral de Cuenca hasta el reinado de Carlos II. Contribución a una historia cítica. Madrid: Editorial Alpuerto.

López Calo, José. 1963. "Corresponsales de Miguel de Irízar» (I). Anuario Musical 17: 197-222.

López Calo, José. 1965. «Corresponsales de Miguel de Irízar» (II). Anuario Musical 20: 209-233.

Martínez Millán, Miguel. 1988. Historia musical de la Catedral de Cuenca. Cuenca: Publicaciones de la Excma. Diputación Provincial.

Mestre Sanchís, Antonio. 2000. «La carta, fuente de conocimiento histórico». Revista de Historia Moderna 18: 13-26.

Olarte Martínez, Matilde. 1996. Miguel de Irízar y Domenzáin (163584?): Biografía, epistolario y estudio de sus lamentaciones. Valladolid: Universidad de Valladolid.

Rodríguez Mateos, Joaquín (ed.). 2009. Un epistolario de Bernardo José Aldrete (1612-1623). Sevilla: Junta de Andalucía. Consejería de Cultura. 